Didáctica. Lengua y literatura

ISSN: 1130-0531

http://dx.doi.org/10.5209/DIDA.57140

\title{
El seminario de lectura en el aula universitaria. Una propuesta: El baile, de Irène Némirovsky
}

\author{
Eva Morón Olivares ${ }^{1}$
}

Recibido: 2 de junio de 2015 / Aceptado: 26 de octubre de 2016

Resumen. Recientes estudios han demostrado el escaso hábito lector de los estudiantes universitarios españoles, así como la falta de solidez de su competencia literaria. Estas limitaciones ponen de relieve la necesidad de la lectura guiada, una propuesta didáctica que suele relacionarse con los niveles iniciales de la enseñanza, pero cuya necesidad se hace cada vez más imperiosa en la educación superior. En este contexto, el presente artículo apuesta por el seminario de lectura como una de las estrategias más efectivas, a la par que estimulantes, para acompañar a los universitarios en ese aprendizaje. Como sugerencia para el docente, desarrollamos un ejemplo a partir de El baile, de Irène Némirovsky

Palabras clave: competencia literaria; valoración de la literatura; habilidades lectoras; hábitos lectores; seminario de lectura; educación superior.

\section{[en] Reading seminars in higher education. A proposal: Le bal, from Irène Némirovsky}

\begin{abstract}
Recent studies have highlighted the poor reading habits of Spanish university students, as well as their lack of solid literary competence. These limitations evidence the need for guided reading, an instructional approach which is usually associated with earlier learning stages, but that is urgently required in higher education. In this context, the following article offers the reading seminar as one of the most effective and stimulating strategies to accompany the students in their learning process. As a suggestion to the lecturer, we develop an example from Le bal, from Irène Némirovsky.

Keywords: literary competence; literature appreciation; reading skills; reading habits; reading seminar; higher education.
\end{abstract}

\section{[fr] Le séminaire de lecture aux cours universitaires. Une proposition: Le bal, de Irène Némirovsky}

Résumé. Des études récentes ont prouvé que les étudiants universitaires espagnols ont rarement l'habitude de lire, et le manque de solidité de sa compétence littéraire. Ces limitations mettent en relief la nécessité de la lecture guidée, une proposition didactique laquelle est souvent rattachée à l'enseignement primaire et secondaire, mais qui devient de plus en plus nécessaire dans l'enseignement universitaire. Dans ce contexte, l'article suivant met l'accent sur le séminaire de lecture pour le souligner comme une des plus solides et encourageantes stratégies pour accompagner aux universitaires dans cet apprentissage. À titre de proposition pour l'enseignant, on a développé un modèle à partir de Le bal, de Irène Némirovsky.

Departamento de Didáctica de la Lengua y la Literatura

Universidad de Valencia (España)

Eva.Moron@uv.es 
Mots clés: compétence littéraire; estimation de la littérature; habiletés pour lire; habitude de lire; séminaire de lecture; enseignement primaire.

Sumario: 1. Introducción. La necesidad de la lectura guiada en el aula universitaria. 2. El seminario de lectura como estrategia metodológica para la educación literaria. 3. Sugerencia para el docente: un seminario de lectura sobre El baile, de Irène Némirovsky. 3.1. Justificación de la obra propuesta. 3.2. Recomendaciones para el docente. 3.3. Fases de la tarea. 3.3.1. Primera fase: selección de temas de interés. 3.3.2. Segunda fase: desarrollo del seminario. 3.3.3. Tercera fase: la evaluación. 4. Conclusiones. 5. Referencias bibliográficas.

Cómo citar: Morón Olivares, E. (2017). El seminario de lectura en el aula universitaria. Una propuesta: El baile, de Irène Némirovsky. Didáctica. Lengua y literatura, 29, 2017, 221-234.

\section{Introducción. La necesidad de la lectura guiada en el aula universitaria}

En los últimos tiempos son numerosas las voces que insisten en la función del lector literario como creador de sentido (Mendoza, 2001; Sánchez Álvarez Isúa, 1999; Sánchez Corral, 2003a y b; Wood, 2009), lo cual significa que un texto literario solo se completa en el juego de hipótesis, relaciones, contrastes, que constituyen la interpretación. Así pues, un lector competente es activo, atento, incluso podríamos calificarlo de sagaz, pues construye su lectura a partir de las pistas que jalonan el texto.

Ahora bien, esta habilidad no es innata del individuo, sino que es fruto de un largo y complejo recorrido. De ahí que la didáctica de la literatura busque el desarrollo de la competencia literaria, entendida más como un conjunto de estrategias y habilidades que como una suma de conocimientos. El profesor debe "crear las condiciones adecuadas para que sean los propios estudiantes los que vayan cuestionando, corrigiendo, evaluando su propio proceso de comprensión y de interpretación [...]" (Jover, 2007, 101).

Ante la dificultad que entraña este aprendizaje, es conveniente recurrir a la lectura guiada; sobre todo en los primeros estadios, que no necesariamente se corresponden con los inicios a la lectura, pues un lector con poca experiencia sigue siendo un lector incipiente. Es cierto que la lectura acompañada encierra algunos peligros, a menudo derivados de que se prime la obra por encima del interés y la capacidad de los lectores; sin embargo, también lo es que este procedimiento hace posible la experimentación de vivencias literarias que de otro modo no se producirían, al tiempo que permite seleccionar obras cuya complejidad aleja a los potenciales lectores.

En el ámbito que nos ocupa, convendría tener en cuenta cuál es el perfil medio del lector universitario español, en el que se han centrado estudios recientes (Colomer y Munita, 2013; Díaz Armas, 2008; Díaz Plaja y Prats, 2013; Larrañaga, Yubero y Cerrillo, 2008; Machado, 2002; Mata, 2008; Morón y Martínez, 2010; Sanjuán Álvarez, 2013; Silva Díaz, 2001; Tabernero, 2013) que evidencian tanto la carencia de hábito lector como la debilidad de su competencia literaria; por ejemplo, leen poca literatura y, cuando lo hacen, se suelen limitar a los best seller; valoran las obras con criterios exclusivamente emocionales; y tienen serias dificultades para establecer 
vínculos intertextuales. En este sentido, el seminario de lectura se revela como una de las propuestas más efectivas, a la par que estimulantes, para acompañar a los universitarios en ese aprendizaje. Eso sí, sin olvidar que es una estrategia válida en cualquier nivel educativo, incluso en Infantil (Chambers, 2007).

\section{El seminario de lectura como estrategia metodológica para la educación literaria}

El seminario es una excelente estrategia para invitar a un grupo a leer de manera detenida y conjunta una obra compleja establecida con antelación.

Muchos de los razonamientos a medias, de las intuiciones vagas, de los variados sentimientos y de las perplejidades que surgen durante la lectura de un libro, se evaporarán rápidamente si se abandonan en su mudo estado original en el interior del estudiante. Pero esos mismos razonamientos y sentimientos pueden convertirse en objetos de atención estables si se expresan en voz alta en una sala llena de gente. Una vez articulados en público, adquieren la posibilidad de empujar hacia adelante el razonamiento (Finkel, 2008, 94).

Podemos definir un seminario como "un espacio físico o escenario donde se construye con profundidad una temática específica del conocimiento en el curso de su desarrollo y a través de intercambios personales entre los asistentes" (Alfaro, 2006, 55). Su objetivo es el debate, la reflexión, el intercambio de ideas y la discusión. En la enseñanza universitaria, es frecuente encontrar seminarios basados tan solo en la disertación del profesor sobre un tema muy específico. En estos casos se pierde de vista el elemento definidor de esta estrategia: la actividad desarrollada por el grupo. Los seminarios están concebidos como espacios de trabajo colectivo, "experiencias de síntesis entre el pensar, el sentir y el actuar, y ello requiere una metodología activa, participativa e interpersonal" (Alfaro, 2006, 56). El éxito de la actividad, el grado de satisfacción y adquisición de competencias que alcancen los participantes, depende de la colaboración de todos.

Las formas de organizarlo son muy variadas, y pueden responder tanto a las características de la disciplina y al tipo de participantes implicados como al tiempo y los recursos disponibles. Las nuevas tecnologías de la información y la comunicación nos permiten, incluso, jugar con la presencialidad y la virtualidad. En la configuración de los grupos puede buscarse la heterogeneidad o, por el contrario, el criterio del estudiante. En cuanto a la frecuencia y duración, dependerán del tipo de tareas y de la preparación que requieran.

Lo importante es que la actividad descanse en el estudiante, que haya una generación continua de ideas y un pensamiento activo, y que se desarrolle la interacción entre los participantes y el sentimiento de pertenencia a un grupo de discusión. Se trata, por tanto, de una de las modalidades más exigentes con el profesor, que debe, entre otras cosas, actuar como guía y dinamizador, pues ha de preguntar, escuchar y propiciar la participación de todos; desarrollar recursos para resolver las situaciones delicadas; actuar como enlace entre las aportaciones de los estudiantes y los contenidos de la disciplina. 
Un seminario permite convertir la docencia en un espacio de reflexión, de argumentación y de crítica, lo que no impide que podamos encontrarnos con ciertos problemas. El primero y más importante es la condición pasiva a la que solemos relegar al estudiante (y en la que este, no nos engañemos, se encuentra a menudo muy cómodo). Ni los estudiantes están acostumbrados a tomar la iniciativa ni los docentes a que la tomen; sin embargo, en esta práctica es determinante que la autoridad se traslade del profesor al grupo. Para que eso ocurra es requisito indispensable, en primer lugar, el convencimiento del docente, su voluntad real de lograr ese trasvase; y en segundo lugar, el empleo de estrategias para evitar que los alumnos no preparen los materiales, como, por ejemplo, mandar breves tareas evaluables y obligatorias para tomar parte en la discusión, adjudicar determinados roles (moderador, juez, abogado del diablo) y recurrir a técnicas que obliguen a todos los componentes a intervenir (cuchicheo o Phillips 66, entre otras). El objetivo último ha de ser desarrollar "la capacidad de participar fructíferamente en una controversia razonada" (Savater, 1997, 136). La clave es aprender a discutir, a refutar, a justificar, para lo cual no basta con expresarse con claridad y precisión; hay que aprender a escuchar y, en especial, a preguntar:

Una de las constataciones más alarmantes de la enseñanza actual es que los maestros de párvulos se ven agobiados por lo mucho que preguntan los niños, mientras que los de la universidad nos quejamos porque jamás preguntan nada. ¿Qué ha pasado en esos años que separan la escuela de las facultades para que se les pasen las gozosas ganas de inquirir? (Savater, 1997, 137-139)

De todo lo anterior se desprende que las ventajas didácticas del seminario en el marco de la educación literaria son incuestionables:

- Brinda la oportunidad de leer de manera más atenta, profunda y compleja

- Posibilita una interpretación conjunta

- Permite elaborar conclusiones personales sobre las lecturas y perder el miedo a la propia voz, a decir lo que se piensa

- Anima a argumentar sobre los libros, por muy difíciles que parezcan en un principio

- Favorece el diálogo entre lectores con distinto bagaje

\section{Sugerencia para el docente: un seminario de lectura sobre El baile, de Irène Némirovsky}

\subsection{Justificación de la obra propuesta}

¿Por qué este libro? Ante todo porque convergen en él dos importantes requisitos: brevedad y extraordinaria calidad literaria. Bajo una equívoca apariencia de simplicidad, se esconde un texto complejo, rico en matices, cuyo mayor logro consiste en el modo en que conjuga concisión e intensidad, desnudez y exactitud. Todo en él está concebido para que el lector no distraiga su mirada, no la aleje de un camino perfectamente trazado por la autora; nada está dejado al azar, todo tiene un lugar preciso y 
lo ocupa. Además, se trata de una autora y un texto todavía bastante desconocidos, sobre los que no es fácil encontrar información. Todas estas razones convierten a $E l$ baile en una lectura muy diferente de las habituales en los alumnos (que, como ya hemos apuntado, suelen decantarse por la literatura comercial), y por tanto constituyen otro motivo para elegirlo, por no mencionar su adaptabilidad a distintos grados no solo de formación literaria, sino también de madurez psicológica, como evidencia la propuesta de Jover (2009).

\subsection{Recomendaciones para el docente}

- El seminario no pertenece al docente, sino al grupo. Esto supone una gran libertad (detenerse en unos aspectos y dejar de lado otros, plantear cualquier duda), pero también exige un alto grado de responsabilidad (leer, pensar, discutir, escuchar, establecer conexiones, rememorar, participar). La función del profesor, por tanto, no es asumir el control cuando el grupo no quiere o no puede continuar, sino participar (plantear sus propias dudas, manifestar perplejidades) y moderar. Es misión del grupo implicarse en que el seminario funcione y en encontrar vías propias para salir de los posibles atolladeros.

- La elección del libro es crucial. En palabras de Finkel (2008, 95): "Bajo el hechizo de un gran libro, los estudiantes sienten que el seminario es necesario, un componente vital de la misma experiencia lectora, nada que ver con un requisito ritual para satisfacer a la profesora". Así pues, debe despertar la curiosidad y ser accesible pero al mismo tiempo implicar un reto interpretativo.

- El profesor ha de asegurarse de que el alumno ha leído el libro al menos una vez antes de comenzar el seminario y varias a lo largo de las diferentes sesiones. Para facilitar esta tarea se recomienda elegir textos breves.

- Que prevalezca la lectura personal no elimina la necesidad de buscar información relevante. El profesor deberá subrayar la necesidad de que las fuentes sean diversas y de calidad.

- Conviene recordar que el seminario va más allá del tiempo de la clase: hay que invitar a los estudiantes a estar abiertos a posibles conexiones con otros discursos (editoriales de prensa, noticias, otros libros, películas, exposiciones de arte...).

- El profesor recomendará a sus alumnos tomar notas durante las sesiones, tanto de las ideas expuestas como de la evolución de la lectura personal (impresiones, sorpresas, aprendizajes, lagunas, descubrimientos, quizá decepciones...). Esto enriquece el seminario y permite comprobar en qué medida ha progresado la interpretación.

- El seminario debería cerrarse siempre con un trabajo que suponga elaboración y síntesis de las posibles repercusiones que la experiencia ha generado en el proceso lector del alumno.

- Es cierto que el seminario es una práctica docente pensada para un reducido número de estudiantes, algo que se aviene mal con la realidad de nuestras aulas; sin embargo, la elección de textos susceptibles de generar sorpresa, interés y curiosidad, minimiza en gran medida este inconveniente. En cualquier caso, siempre podemos recurrir a fórmulas como dividir la clase en grupos más pequeños. 
- Por último, sugerimos una disposición de las mesas propicia para el diálogo (si es posible, en círculo: nadie ocupa un lugar preeminente y facilita el intercambio de pareceres).

\subsection{Fases de la tarea}

\subsubsection{Primera fase: selección de temas de interés}

El primer paso será establecer un calendario de trabajo que proporcione a los estudiantes una visión clara de la estructura del seminario. A continuación, conviene fijar una tarea evaluable y obligatoria que asegure una primera lectura y ayude al profesor a encontrar las vías de acercamiento al texto idóneas para el grupo. Podría consistir en responder por escrito a algunas cuestiones, extraídas de una relación más amplia, acerca de las primeras impresiones obtenidas. Ofrecemos a continuación algunas sugerencias inspiradas en las conversaciones literarias de Chambers (2007). A partir de las líneas de interés manifestadas por los alumnos, el profesor podrá reordenarlas o añadir otras que considere relevantes.

- La primera vez que viste el libro, ¿qué clase de libro pensaste que sería? ¿Qué te hizo pensar eso? Ahora que ya lo has leído, ¿es lo que esperabas?

- ¿Esta obra tiene algo que ver contigo, te ves reflejado, implicado, afectado, te sientes interpelado por ella?

- ¿Te ha resultado fácil, difícil? ¿Por qué?

- ¿Hubo algo que te gustara, que te llamara la atención de un modo especial, que hubieras querido que estuviera más presente?

- ¿Hubo algo que no te gustara, como, por ejemplo, partes que te aburrieron o alguna que te saltaras o desearas hacerlo? ¿Te dieron ganas de dejar la lectura?

- ¿Hubo algo que te desconcertara (algo que nunca antes habías visto en un libro, que te pareciera extraño, que te tomara totalmente por sorpresa)?

- ¿Cambiarías algo? ¿Hay algo que hubieras preferido que fuera de otra forma?

- Mientras leías, ¿encontraste palabras o frases o alguna otra cosa que tenga que ver con el lenguaje que te gustara o que no te gustara?

- ¿Puedes establecer algún vínculo entre esta obra y otras que conozcas, literarias o no?

- ¿Recomendarías este libro a alguien? ¿Por qué?

- ¿De qué crees que habla El baile?

- ¿Sabes algo sobre la autora, sobre la época en la que escribió?

Tabla 1. Posibles preguntas para seleccionar temas de interés e iniciar la discusión

\subsubsection{Segunda fase: desarrollo del seminario}

Uno de los grandes riesgos de un seminario es que se convierta en un frívolo intercambio de impresiones. Para evitarlo, el profesor ha de prepararlo de forma muy concienzuda y, por una parte, prever los posibles hilos de discusión y, por otra, estar 
abierto a las sorpresas que sin duda se producirán en una situación como esta. Su objetivo no será nunca monopolizar la conversación, sino sortear los posibles puntos muertos o llamar la atención sobre algún aspecto interesante que haya pasado desapercibido. En palabras de Meirieu $(2002,100)$ : "Si el rol del maestro es, en verdad, el de hacer surgir el deseo de aprender, su tarea reside en 'crear el enigma' [...]".

Son muchas las formas en que se puede organizar un seminario; quizá entre las más esclarecedoras estén las que aporta Finkel (2008) y que giran en torno a la importancia de que tanto los alumnos como el profesor aporten más preguntas que respuestas: obligan a pensar la lectura, a plantear cuestiones susceptibles de despertar el interés de los asistentes y a evaluar la calidad de los interrogantes. Un seminario no es sino una indagación conjunta: cuanto mejores sean las preguntas, más rico será el debate y más posibilidades habrá de que se mantenga abierto y vivo después de la clase.

De todo lo anterior se desprende que los focos de atención variarán mucho de uno a otro grupo. A modo de ejemplo, ofrecemos los que nos parece que encierran más posibilidades en el caso de El baile y que se centran en contexto y género, lenguaje, y temas e intertextualidad.

El bloque de contexto y género puede desarrollarse en torno a varios interrogantes como los que proponemos a continuación.

\section{¿Es El baile una novela autobiográfica?}

Esta pregunta busca erradicar la habitual confusión que se establece entre la vida de un autor y su obra. En este caso, las concomitancias son evidentes: mala relación de Némirovsky con su madre, familia judía pudiente, París como escenario. Sin embargo, de ahí no puede deducirse que la novela sea una traslación directa de la vida de la autora: la materia vital es solo uno de los componentes que usa el novelista para fabular. El pacto de la ficción supone aceptar a un tiempo lo real y lo que aparenta serlo, lo verificable y lo verídico; el novelista no busca relatar la historia, sino su historia; no lo que fue, sino lo que podría haber sido, y toda su capacidad e ingenio se ponen al servicio de esa labor creativa.

Además, en este caso concreto convendría no perder de vista la identidad escurridiza de la autora (ucraniana, pero alejada de los exiliados rusos; políglota, pero elige como lengua literaria el francés; judía, pero publica artículos en revistas antisemitas y acaba por convertirse al catolicismo), lo cual hace todavía más difícil rastrear los posibles datos autobiográficos de su obra.

¿Por qué una novela corta?

Podemos presumir que responde a un intento de explorar fórmulas narrativas no convencionales (algo en línea con otros autores de la época, como Joyce, Woolf, Dos Passos, que por caminos muy diversos están rompiendo los límites de la novela decimonónica). Por otro lado, es un claro reto compositivo: bajo la apariencia de un divertimento, de algo simple e intrascendente, se esconde una auténtica carga de profundidad. Quizá por eso, aunque parece dirigirse a todo tipo de lector, en realidad apela a un lector avezado, alerta, que disfruta con el cuidadoso entramado que constituye la obra. La de El baile es una complejidad que pone en evidencia la distancia entre un lector medio, que se queda solo con la trama de la novela, y un lector experto, capaz de apreciar el trabajo de orfebrería que la sustenta. Por no mencionar que es una novela tan densa en todos los niveles que no podría sostenerse en un texto de mayor extensión. 


\section{¿Cómo es la voz narradora de El baile?}

Se trata de una utilización de la narración omnisciente muy personal, en consonancia con ese principio constructor de desnudez, esencialidad, precisión, condensación, que es el motor de la novela. Este procedimiento llega al extremo de desvelar tan solo los pensamientos de las dos protagonistas y, además, en apenas un par de frases: Antoinette ("Tenía catorce años, era una jovencita y, en sus sueños, una mujer amada y hermosa... Los hombres la acariciaban, la admiraban, [...]") y Rosine ("Cómo había que apresurarse en vivir, Dios mío, en agradar a los hombres, en amar...”). Tampoco se nos proporcionan detalles de la apariencia de los personajes, solo los rasgos que mejor definen su carácter (los "ojos brillantes" del señor Kampf, apodado "Feuer"; la "voz torpe y fresca" de la apocada institutriz; o la figura de Isabelle, "flaca, envarada y tiesa como un paraguas").

Tabla 2. Contexto y género

El desarrollo del apartado sobre el lenguaje podría girar en torno a cuestiones como las que siguen:

\section{¿Cuál es el color dominante de El baile?}

Esta pregunta, que puede parecer desconcertante, sirve para llamar la atención sobre un punto clave de la novela que, si bien suele pasar desapercibido a un lector no experimentado, es quizá el ejemplo más representativo del cuidadoso trabajo de condensación narrativa de Némirovsky. En un escenario blanco y negro (un gran piso blanco de artesonados blancos, el cielo blanco como una perla, Sena negro, la regla de ébano de Isabelle), destacan los brillos (las ventanas brillantes, la ropa interior de seda, las luces rutilantes); los sonidos tintineantes (la araña de cristal con su sonido de cascabel, el crujido de la seda de la ropa interior o del canapé, el tintineo de la cristalería), que acaban convirtiéndose en una amenaza (la orquesta que brama en el salón desierto, el rechinar de las mandíbulas de Rosine o el siseo entre dientes de Kampf); y la sensación de frialdad que se desprende de las referencias al hielo, la habitación helada, la noche pura y fría, los cristales fríos. La conjunción de estos elementos (blanco y negro, brillo, tintineo y frialdad) subraya la ausencia de emociones positivas (afecto, calidez, alegría), así como el afán de aparentar. Rosine ha preparado un escenario para brillar y en el que sueña con desempeñar el papel protagonista, pero que acabará siendo la tumba de sus aspiraciones sociales.

Los únicos toques de color tienen una función muy determinada: el amarillo del jarrón de casa de Isabelle, así como el del vestido y los escarpines que calza el día de la fiesta encierran en su interior, el primero suciedad, el segundo un alma venenosa. Recordemos que el amarillo es un color maldito para la escena desde la muerte de Molière, y que el baile de los Kampf es toda una puesta en escena). En cuanto a los zafiros, rubíes y esmeraldas (cuyos colores son parecidos a los que despliega en su cola el pavo real), unidos a todos los diamantes y perlas que lleva Rosine la noche fatídica, no hacen sino subrayar sus ansias de lucirse. 


\section{¿Es sencillo El baile?}

La primera lectura a menudo produce esa impresión, que pronto se revela engañosa. Y es que El baile es una obra pensada al milímetro, en la que todos y cada uno de sus elementos forman parte de un engranaje ensamblado con precisión absoluta. Nada queda al azar; cualquier palabra, cualquier imagen, cualquier referencia tiene un sentido, y descubrir ese trabajo de orfebre es un reto y un placer para el lector atento. Por ejemplo, no hay descripciones detalladas ni de los espacios (París queda reducida a tres referencias: el Bois, el puente de Alejandro III y el Sena); ni de los tiempos (solo sabemos que es otoño -"oscura calle otoñal"-; incluso un hecho tan trascendental como el súbito enriquecimiento de la familia protagonista se resuelve en esta frase: "Y después, un buen día se hicieron ricos de golpe"); ni de los personajes, salvo alguna breve indicación (del físico de Antoinette solo sabemos que su rostro es pálido y descarnado, "una mancha redonda y clara, sin rasgos, con los párpados bajos, ojerosos, la pequeña boca cerrada"; y de Rosine, tan solo conocemos su "cabellera resplandeciente"). Se ha dejado solo lo imprescindible; la técnica de Némirovsky es eliminar, borrar todo aquello que no sea esencial para la historia que se ha propuesto contar.

Tabla 3. Lenguaje

También en temas y vínculos intertextuales encontramos muy sugerentes vías de aproximación:

\section{Antoinette y Rosine, ¿dos caras de la misma moneda?}

En un primer momento ambas pueden parecer distintas; además, la extrema brusquedad y la vulgaridad de Rosine hacen parecer a Antoinette inocente. Sin embargo, una calculada sucesión de pistas nos irá dando la auténtica medida del personaje y la similitud que guarda con el de su madre. Por ejemplo, ambas leen las mismas novelas románticas y aspiran al mismo ideal: ser "una mujer amada y hermosa"; ambas se reconocen como enemigas y juegan con la idea de la muerte de la otra; ambas tienen los mismos gestos (pegan el rostro a los cristales fríos y se retuercen las manos de modo tan idéntico que Antoinette se sobresalta "como cuando te encuentras repentinamente ante un espejo"). Por último, ambas se miran con una suerte de condescendencia que las lleva a exclamar "pobre hija mía" y "pobre mamá" al final del primer y último capítulo respectivamente.

A pesar de estas similitudes, existen importantes diferencias entre ellas. Rosine se muestra tal cual es: brusca, vulgar, "con modales de verdulera" que no pueden disimular todas las joyas que posee, tan ridícula en sus aspiraciones que resulta patética ("El dinero, los vestidos y los coches bonitos, ¿de qué servía todo eso sin un hombre en tu vida, un pretendiente, un joven amante?"). Antoinette, sin embargo, pese a tener aspiraciones similares, es taimada, incluso perversa, como revela el silencio que mantiene tras el arrebato que desencadenará el momento culminante de la novela. 
¿Qué función cumplen en la obra de Némirovsky los vínculos intertextuales?

En primer lugar habría que destacar que, como todo en esta obra, están muy seleccionados: ni son gratuitos ni irrelevantes. Así tenemos, por ejemplo, los títulos que leen Antoinette $\mathrm{y}$, cabe presumir, su madre, quienes sueñan con los personajes de Il piacere, de Gabriele d'Annunzio, y Les demi vierges, de Marcel Prévost. De un modo más indirecto, pero cargado de sarcasmo, se hace alusión a Celimena, protagonista de El misántropo, de Molière; es Isabelle, "malévola y fisgona como una vieja beata", quien mueve el abanico como esta joven atractiva y siempre rodeada de pretendientes; es más, el vestido mismo que luce en la fiesta remite al color maldito de la escena francesa, el amarillo. Otro ejemplo del modo magistral en que Némirovsky dibuja a los personajes con pinceladas breves y exactas es la referencia a Medusa para describir a la Rosine auténtica antes de ocultarse tras los brillos del lamé y los diamantes: "sus despeinados cabellos se retorcían como serpientes en torno a su rostro encendido". Una Medusa, en este caso, patética porque, en lugar de infundir terror, solo consigue provocar la burla y el desprecio.

Por último, no querríamos dejar de mencionar el modo en que la autora maneja la siempre compleja relación madre-hija, pues si bien la figura de la madrastra o de la madre cruel no están ausentes incluso del cuento tradicional, es menos frecuente encontrarse con una hija de aspecto desvalido pero cuyo comportamiento solo puede calificarse de pérfido.

Tabla 4. Temas y vínculos intertextuales

\subsubsection{Tercera fase: la evaluación}

Está claro que la evaluación de una propuesta como la que aquí ofrecemos no puede seguir los cauces convencionales, sino que ha de incidir en lo que constituye la esencia del seminario: la reflexión, la justificación del punto de vista personal. Por ello, si la discusión oral propicia los interrogantes y la apertura de nuevas vías de aproximación al texto, la tarea debe concluir con un ensayo individual que facilite la introspección y el autoconocimiento. Como señala Finkel $(2008,94)$ : “[...], el seminario no es muy útil para refinar los resultados del estudio del texto. Es más probable que los últimos pasos de la indagación los faciliten tareas de escritura". Este autor va todavía más allá al afirmar que "los estudiantes deben concebir la escritura como 'pensar sobre el papel', no solo como un medio de informar de los resultados de su razonamiento" (2008, 143).

El ensayo es una de las mejores opciones porque el autor ha de partir de una perspectiva subjetiva y a la vez rigurosa, pero sin incluir datos exhaustivos de la imprescindible indagación que el género requiere; indagación que es a un tiempo introspectiva (ideas preconcebidas, experiencia de lectura, reflexión, creencias) y erudita (datos relevantes, conceptos propios de la materia, respeto por las normas del género). Es un género híbrido en el que chocan, por un lado, el interés personal del autor por explorar un tema (lo que permite que afloren sus convicciones, dudas, hallazgos o perplejidades), y por otro, la exigencia de una escritura rigurosa, sólida y clara.

En el ensayo son tan importantes el desarrollo lógico de las ideas, los datos contrastados, los argumentos convincentes, los ejemplos significativos (rasgos típicos del texto científico o académico), como encontrar el ritmo adecuado, imágenes poderosas o la palabra precisa (rasgos consustanciales al texto literario). Además, presupone en el autor la suficiente honestidad intelectual como para que haya efectuado 
las comprobaciones pertinentes, lo que otorga al texto la solidez necesaria como para ser tomado en serio.

A continuación proponemos una tabla con criterios útiles para evaluar un trabajo de estas características.

\begin{tabular}{|c|c|c|c|}
\hline & Mal & De regular a bien & Muy bien \\
\hline $\begin{array}{l}\text { Aprovechamien- } \\
\text { to del seminario }\end{array}$ & $\begin{array}{l}\text { El trabajo evidencia } \\
\text { una lectura superfi- } \\
\text { cial y una absoluta } \\
\text { impermeabilidad } \\
\text { a cualquiera de las } \\
\text { vías abiertas duran- } \\
\text { te el seminario. No } \\
\text { ha participado y, } \\
\text { por ello, no ha reci- } \\
\text { bido retroalimenta- } \\
\text { ción sobre sus ideas } \\
\text { iniciales }\end{array}$ & $\begin{array}{l}\text { El trabajo evidencia } \\
\text { una lectura básica. } \\
\text { Se limita a resumir lo } \\
\text { ocurrido en el semi- } \\
\text { nario. Es la tarea de } \\
\text { un receptor, no de un } \\
\text { productor de ideas. El } \\
\text { seminario es un punto } \\
\text { de llegada }\end{array}$ & $\begin{array}{l}\text { El trabajo evidencia } \\
\text { una lectura atenta, una } \\
\text { actitud abierta a com- } \\
\text { pletar, discutir y con- } \\
\text { trastar las ideas per- } \\
\text { sonales con las que se } \\
\text { han aportado en el se- } \\
\text { minario. El seminario } \\
\text { es un punto de partida, } \\
\text { no de llegada }\end{array}$ \\
\hline $\begin{array}{l}\text { Interpretación } \\
\text { personal }\end{array}$ & $\begin{array}{l}\text { Falta de criterio, } \\
\text { uso abusivo de } \\
\text { fuentes ajenas }\end{array}$ & $\begin{array}{l}\text { No confía en sus pro- } \\
\text { pias reflexiones y las } \\
\text { supedita a opiniones } \\
\text { ajenas }\end{array}$ & $\begin{array}{l}\text { Establece vínculos en- } \\
\text { tre su interpretación y } \\
\text { la de otros, relaciona el } \\
\text { texto con otros, litera- } \\
\text { rios o no }\end{array}$ \\
\hline $\begin{array}{l}\text { Preparación y es- } \\
\text { tructura }\end{array}$ & $\begin{array}{l}\text { Improvisación, au- } \\
\text { sencia de un hilo } \\
\text { conductor, suma } \\
\text { de ideas inconexas, } \\
\text { pobreza de ideas, } \\
\text { repeticiones, falta } \\
\text { de estructura }\end{array}$ & $\begin{array}{l}\text { Algún dato poco asi- } \\
\text { milado, algún fallo } \\
\text { de estructura, reitera- } \\
\text { ciones, manejo de un } \\
\text { número limitado de } \\
\text { ideas }\end{array}$ & $\begin{array}{l}\text { Buena disposición } \\
\text { de las partes, uso de } \\
\text { fuentes ajenas para } \\
\text { enriquecer la propia } \\
\text { lectura, se condensa y } \\
\text { sintetiza con eficacia la } \\
\text { información obtenida, } \\
\text { manejo de una amplia } \\
\text { variedad de ideas }\end{array}$ \\
\hline Argumentación & $\begin{array}{l}\text { Su exposición es } \\
\text { pobre, carece de } \\
\text { fuerza, no es creí- } \\
\text { ble, resulta falsa }\end{array}$ & $\begin{array}{l}\text { Ofrece argumentos } \\
\text { que hablan de su ex- } \\
\text { periencia lectora }\end{array}$ & $\begin{array}{l}\text { Ofrece argumentos y } \\
\text { ejemplos claros y fun- } \\
\text { damentados que dan } \\
\text { una imagen exacta de } \\
\text { su experiencia lectora } \\
\text { y pueden iluminar el } \\
\text { camino de los demás }\end{array}$ \\
\hline $\begin{array}{l}\text { Respeto por las } \\
\text { normas del géne- } \\
\text { ro ensayístico }\end{array}$ & $\begin{array}{l}\text { No respeta las } \\
\text { normas, no es un } \\
\text { ensayo, sino una } \\
\text { enumeración de } \\
\text { aspectos heterogé- } \\
\text { neos del texto }\end{array}$ & $\begin{array}{l}\text { Respeta las normas } \\
\text { pero no logra un tono } \\
\text { personal; enumera } \\
\text { elementos, referencias } \\
\text { sin buscarles un sen- } \\
\text { tido; en ocasiones la } \\
\text { voz resulta impostada }\end{array}$ & $\begin{array}{l}\text { Logra un tono perso- } \\
\text { nal, hay un considera- } \\
\text { ble nivel de introspec- } \\
\text { ción, se aprecia una } \\
\text { búsqueda de sentido } \\
\text { a la propia lectura, la } \\
\text { voz del texto resulta } \\
\text { veraz }\end{array}$ \\
\hline
\end{tabular}




\begin{tabular}{|c|c|c|c|}
\hline $\begin{array}{l}\text { Respeto por las } \\
\text { normas del tra- } \\
\text { bajo académico }\end{array}$ & $\begin{array}{l}\text { Traslada sin re- } \\
\text { flexión ideas aje- } \\
\text { nas; enumera datos, } \\
\text { ejemplos e ideas } \\
\text { sin buscarles sen- } \\
\text { tido; no usa fuen- } \\
\text { tes apropiadas; no } \\
\text { ofrece un punto de } \\
\text { vista personal }\end{array}$ & $\begin{array}{l}\text { Se esfuerza en la con- } \\
\text { sulta de fuentes y en la } \\
\text { búsqueda de argumen- } \\
\text { tos, pero el resultado } \\
\text { no es del todo satis- } \\
\text { factorio; trivializa la } \\
\text { información maneja- } \\
\text { da; respeta las normas } \\
\text { pero no logra un tono } \\
\text { personal }\end{array}$ & $\begin{array}{l}\text { La consulta de fuentes } \\
\text { es amplia, adecuada y } \\
\text { está al servicio de la } \\
\text { perspectiva personal; } \\
\text { asimila las ideas: hay } \\
\text { un contrapunto exitoso } \\
\text { entre la información } \\
\text { obtenida y el propósito } \\
\text { que se persigue; la voz } \\
\text { del texto resulta veraz }\end{array}$ \\
\hline Registro formal & $\begin{array}{l}\text { Usa un registro } \\
\text { inadecuado (colo- } \\
\text { quial, redundante, } \\
\text { amanerado...) }\end{array}$ & $\begin{array}{l}\text { Utiliza un registro for- } \\
\text { mal con errores (co- } \\
\text { loquialismos, pobreza } \\
\text { léxica, uso poco fluido } \\
\text { de conectores, algún } \\
\text { anacoluto...) }\end{array}$ & $\begin{array}{l}\text { Utiliza el registro aca- } \\
\text { démico formal (léxi- } \\
\text { co variado y preciso, } \\
\text { estructura gramatical } \\
\text { correcta...) }\end{array}$ \\
\hline $\begin{array}{l}\text { Utilización de las } \\
\text { tutorías }\end{array}$ & $\begin{array}{l}\text { Acude pero espe- } \\
\text { rándolo todo de la } \\
\text { profesora }\end{array}$ & $\begin{array}{l}\text { Acude y las utiliza } \\
\text { para introducir mejo- } \\
\text { ras puntuales }\end{array}$ & $\begin{array}{l}\text { Dialoga activamente, } \\
\text { hace propuestas, busca } \\
\text { siempre fórmulas para } \\
\text { mejorar el texto }\end{array}$ \\
\hline
\end{tabular}

Tabla 5. Criterios de evaluación

\section{Conclusiones}

Si nos esforzamos por que la experiencia sea exitosa, todos los participantes saldrán beneficiados. Es cierto, como afirmábamos al principio, que el estudiante universitario suele ser un lector de escasa competencia y que un seminario de lectura puede servir para paliar sus carencias, pero no lo es menos que esta estrategia desarrolla también otras habilidades, ligadas al discurso oral y al trabajo en grupo, indispensables en la educación superior y que en nuestro país siguen sin recibir la necesaria atención en las distintas etapas educativas. Hablamos de la escucha activa, de la exposición y argumentación orales, del uso del registro académico formal, por no mencionar la decantación del punto de vista y la asunción de la responsabilidad personal en el aprendizaje. Pero también para el docente un seminario puede ser una excelente ocasión de aprendizaje, pues una experiencia como esta le invita, por una parte, a relegar el papel de juez y a asumir, en su lugar, el papel de guía, y por otra, a renunciar a poseer todas las respuestas. El profesor, en última instancia, participa como un lector más, con sus dudas, hipótesis y hallazgos; en la medida en que sepa ofrecerlos con humildad, pero también con plena consciencia e incluso, por qué no, con cierta picardía, servirán como acicate para estos lectores de limitada trayectoria. En palabras de Chambers $(2007,34)$ :

El efecto público de esta reunión consciente de ideas es que logramos una 'lectura' - un conocimiento, entendimiento, apreciación - de un libro que excede ampliamente lo que cada uno de los miembros del grupo podría haber logrado solo. Cada miembro sabe una parte, pero ninguno sabe todo. 
Si somos afortunados, la experiencia podrá llegar a ser casi iniciática: "La sensación es 'de despegue', de volar hacia lo que hasta ahora era desconocido: la experiencia de la revelación” $(2007,35)$.

\section{Referencias bibliográficas}

Alfaro, Ignacio Javier (2006): "Seminarios y talleres", en Metodologías de enseñanza y aprendizaje para el desarrollo de competencias, De Miguel, M. (ed.), Madrid, Alianza, 53-82.

Colomer, Teresa y Munita, Felipe (2013): "La experiencia lectora de los alumnos de magisterio: nuevos desafíos para la formación docente", Lenguaje y Textos, 38, 37-45.

Chambers, Aidan (2007): Dime: los niños, la lectura y la conversación, México, Fondo de cultura económica.

Díaz Armas, Jesús (2008): "Lectura literaria y formación inicial: creencias del profesorado en formación sobre el texto y su lector", en Textos entre textos: las conexiones textuales en la formación del lector, Mendoza Fillola, A. (coord.), Barcelona, Horsori, 177-190.

Díaz-Plaja, Ana y Prats, Margarida (2013): "Recordar, aprender, practicar: qué sabe y qué debe saber un futuro maestro", Lenguaje y Textos, 38, 19-28.

Finkel, Don (2008): Dar clase con la boca cerrada, Valencia, Universidad de Valencia.

Jover, Guadalupe (2007): Un mundo por leer. Educación, adolescentes y literatura, Barcelona, Octaedro.

Jover, Guadalupe (coord.) (2009): Constelaciones literarias. Sentirse raro. Miradas sobre la adolescencia, Málaga, Junta de Andalucía/Bibliotecas escolares de la provincia de Málaga.

Larrañaga, Elisa; Yubero, Santiago; y Cerrillo, Pedro (2008): Estudio sobre los hábitos de lectura de los universitarios españoles, Madrid, SM.

Machado, Ana M $\mathrm{M}^{\mathrm{a}}$ (2002): Lectura, escuela y creación literaria, Madrid, Anaya.

Meirieu, Philippe (2002): Aprender, sí. Pero ¿cómo?, Barcelona, Octaedro.

Mendoza Fillola, Antonio (2001): El intertexto lector. El espacio de encuentro de las aportaciones del texto con las del lector, Cuenca, Universidad de Castilla-La Mancha.

Morón, Eva y Martínez, Consuelo (2010): "Dar de leer: propuestas para la formación literaria de futuros maestros", Cuadernos de Literatura Infantil y Juvenil, 236, 53-59.

Némirovsky, Irène (2006): El baile, Barcelona, Salamandra [orig. 1930].

Sánchez Álvarez-Isúa, Alberto (1999): "De cómo un texto deviene literatura", Enrahonar: Cuaderns de Filosofia, 30, 75-87.

Sánchez Corral, Luis (2003a): "Didáctica de la literatura: relaciones entre el discurso y el sujeto", en Didáctica de la lengua y la literatura, Mendoza Fillola, A. (coord.), Madrid, Pearson Educación, 291-318.

Sánchez Corral, Luis (2003b): "De la competencia literaria al proceso educativo: actividades y recursos", en Didáctica de la lengua y la literatura, Mendoza Fillola, A. (coord.), Madrid, Pearson Educación, 319-348.

Sanjuán Álvarez, Marta (2013): “Aprender literatura en la escuela: una investigación etnográfica”, Lenguaje y Textos, 38, 179-188.

Savater, Fernando (1997): El valor de educar, Barcelona, Ariel.

Silva Díaz, M ${ }^{a}$ Carmen (2001): "La formación de los maestros en literatura infantil: un es- 
tudio diagnóstico", en Geografías lectoras: nuevos proyectos y realidades en la lectura infantil y juvenil, Goldin, D. et al., Salamanca, Fundación Germán Sánchez Ruipérez, 83-92.

Tabernero, Rosa (2013): "El lector literario en los grados de Maestro: deconstruir para construir", Lenguaje y Textos, 38, 47-56.

Wood, James (2009): Los mecanismos de la ficción: cómo se construye una novela, Madrid, Gredos. 